\title{
The Optimal Inflation TARget in AN ECONOMY WITH LIMITED ENFORCEMENT
}

Gaetano Antinolfi

Washington University

Costas Azariadis

Washington University and FRB-St. Louis

James Bullard*

Federal Reserve Bank of St. Louis

2 October 2008

Indiana University

* Views expressed are those of the author and do not necessarily reflect official positions of the FOMC or the Federal Reserve 


\section{COMFORT ZONES}

- Typical FOMC member statements: 1 to 2 percent inflation would be ideal.

- "Small positive inflation is the best inflation target."

- Associated with short-term nominal interest rates near 5 percent.

- Economic theory: nominal interest rates should be zero.

- Why the difference? 


\section{THEORY AND REALITY: WHY THE DIFFERENCE?}

- Japan.

- Summers (1991): Zero bound on nominal interest rates interferes with stabilization policy.

- Adam and Billi (2006).

- Smith (2002). Deflation causes disintermediation, harming the operation of credit markets.

- We study a version of the latter:

- A small amount of inflation "deepens financial markets" in a way we make precise. 


\section{WHAT WE DO}

- Endowment economy with constant aggregate income. 


\section{WHAT WE DO}

- Endowment economy with constant aggregate income.

- A continuum of infinitely-lived households. 


\section{WHAT WE DO}

- Endowment economy with constant aggregate income.

- A continuum of infinitely-lived households.

- Endowments fluctuate. 


\section{WHAT WE DO}

- Endowment economy with constant aggregate income.

- A continuum of infinitely-lived households.

- Endowments fluctuate.

- Two assets: currency and consumption loans. 
- Households are divided into two types. 


\section{AgENT TYPeS}

- Households are divided into two types.

- "Townsend-Bewley-type" or cash agents can only use currency in nonnegative amounts to smooth consumption. 


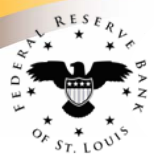

\section{AgENT TYPeS}

- Households are divided into two types.

- "Townsend-Bewley-type" or cash agents can only use currency in nonnegative amounts to smooth consumption.

- "Kehoe-Levine-type" or credit agents can participate in either asset market subject to endogenous debt constraints. 


\section{AgENT TYPeS}

- Households are divided into two types.

- "Townsend-Bewley-type" or cash agents can only use currency in nonnegative amounts to smooth consumption.

- "Kehoe-Levine-type" or credit agents can participate in either asset market subject to endogenous debt constraints.

- Default is punished by perpetual exclusion from the loan market but still permits defaulting households to hold nonnegative currency. 
- Households are divided into two types.

- "Townsend-Bewley-type" or cash agents can only use currency in nonnegative amounts to smooth consumption.

- "Kehoe-Levine-type" or credit agents can participate in either asset market subject to endogenous debt constraints.

- Default is punished by perpetual exclusion from the loan market but still permits defaulting households to hold nonnegative currency.

- Inflation will make default less attractive, loosening participation constraints and strengthening the credit market. 


\section{PREVIEW OF MAIN FINDINGS}

- We study a particular social planning problem, made precise below. 


\section{PREVIEW OF MAIN FINDINGS}

- We study a particular social planning problem, made precise below.

- Deflation is infeasible if the planner assigns positive weight to credit households. 


\section{PREVIEW OF MAIN FINDINGS}

- We study a particular social planning problem, made precise below.

- Deflation is infeasible if the planner assigns positive weight to credit households.

- Inflation higher than the level required to slacken debt constraints will not be chosen if the planner assigns sufficient weight to cash households. 


\section{PREVIEW OF MAIN FINDINGS}

- We study a particular social planning problem, made precise below.

- Deflation is infeasible if the planner assigns positive weight to credit households.

- Inflation higher than the level required to slacken debt constraints will not be chosen if the planner assigns sufficient weight to cash households.

- If the planner puts a relative weight greater than zero but less than the population weight on credit households, the optimum inflation rate is positive. 


\section{PREVIEW OF MAIN FINDINGS}

- We study a particular social planning problem, made precise below.

- Deflation is infeasible if the planner assigns positive weight to credit households.

- Inflation higher than the level required to slacken debt constraints will not be chosen if the planner assigns sufficient weight to cash households.

- If the planner puts a relative weight greater than zero but less than the population weight on credit households, the optimum inflation rate is positive.

- Conclude: Independent central banks will set low positive inflation targets in economies that possess highly developed financial markets. 


\section{RECENT RELATED LITERATURE}

- Aiyagari and Williamson (2000 JET).

- Related environment, random endowments, outside option is Bewley, emphasis on financial intermediation, positive inflation deters default, computational.

- Berentsen, Camera and Waller (2007 JET).

- Related environment, Lagos-Wright, emphasis on financial intermediation, positive inflation deters default.

- Ragot (2007). OLG framework.

- Andolfatto (2007).

- Antinolfi, Azariadis, and Bullard (2007).

- Money is the only asset, emphasis on dynamics and equilibrium selection.

- Sanchez, Williamson, and Wright (2007). Blackboard version. 
- Continuum of infinitely-lived households. 


\section{ENVIRONMENT}

- Continuum of infinitely-lived households.

- $\lambda$ "Kehoe-Levine" or credit type agents. 


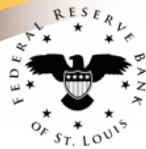

\section{ENVIRONMENT}

- Continuum of infinitely-lived households.

- $\lambda$ "Kehoe-Levine" or credit type agents.

- $1-\lambda$ "Townsend-Bewley" or cash type agents. 


\section{ENVIRONMENT}

- Continuum of infinitely-lived households.

- $\lambda$ "Kehoe-Levine" or credit type agents.

- $1-\lambda$ "Townsend-Bewley" or cash type agents.

- All types have identical preferences

$$
\sum_{t=0}^{\infty} \beta^{t} u\left(c_{t}^{i}\right)
$$

with discount factor $0<\beta<1, u(c)$ standard, and $i=0,1,2,3$. 


\section{ENDOWMENTS}

- Credit households are divided into two sub-types, 0 and 1, with mass $\lambda / 2$ each. 


\section{ENDOWMENTS}

- Credit households are divided into two sub-types, 0 and 1, with mass $\lambda / 2$ each.

- Cash households are divided into two sub-types, 2 and 3, with mass $1-\lambda / 2$ each. 


\section{ENDOWMENTS}

- Credit households are divided into two sub-types, 0 and 1, with mass $\lambda / 2$ each.

- Cash households are divided into two sub-types, 2 and 3, with mass $1-\lambda / 2$ each.

- Endowments, interpreted as income shares, are periodic:

$$
\left(\omega_{t}^{0}, \omega_{t}^{1}\right)=\left(\omega_{t}^{2}, \omega_{t}^{3}\right)= \begin{cases}(1+\alpha, 1-\alpha) & \text { if } t=0,2, \ldots \\ (1-\alpha, 1+\alpha) & \text { if } t=1,3, \ldots\end{cases}
$$




\section{ENDOWMENTS}

- Credit households are divided into two sub-types, 0 and 1, with mass $\lambda / 2$ each.

- Cash households are divided into two sub-types, 2 and 3, with mass $1-\lambda / 2$ each.

- Endowments, interpreted as income shares, are periodic:

$$
\left(\omega_{t}^{0}, \omega_{t}^{1}\right)=\left(\omega_{t}^{2}, \omega_{t}^{3}\right)= \begin{cases}(1+\alpha, 1-\alpha) & \text { if } t=0,2, \ldots \\ (1-\alpha, 1+\alpha) & \text { if } t=1,3, \ldots\end{cases}
$$

- $\alpha \in(0,1)$ indexes the degree of income volatility. 


\section{ENDOWMENTS}

- Credit households are divided into two sub-types, 0 and 1, with mass $\lambda / 2$ each.

- Cash households are divided into two sub-types, 2 and 3, with mass $1-\lambda / 2$ each.

- Endowments, interpreted as income shares, are periodic:

$$
\left(\omega_{t}^{0}, \omega_{t}^{1}\right)=\left(\omega_{t}^{2}, \omega_{t}^{3}\right)= \begin{cases}(1+\alpha, 1-\alpha) & \text { if } t=0,2, \ldots \\ (1-\alpha, 1+\alpha) & \text { if } t=1,3, \ldots\end{cases}
$$

- $\alpha \in(0,1)$ indexes the degree of income volatility.

- Aggregate income is constant. 


\section{NATURE OF THE ENVIRONMENT}

- Cash agents are anonymous households who may only use currency to smooth income fluctuations, as in Bewley (1980). 


\section{NATURE OF THE ENVIRONMENT}

- Cash agents are anonymous households who may only use currency to smooth income fluctuations, as in Bewley (1980).

- No claims can be enforced on them or by them. 


\section{NATURE OF THE ENVIRONMENT}

- Cash agents are anonymous households who may only use currency to smooth income fluctuations, as in Bewley (1980).

- No claims can be enforced on them or by them.

- The "unbanked." 


\section{NATURE OF THE ENVIRONMENT}

- Cash agents are anonymous households who may only use currency to smooth income fluctuations, as in Bewley (1980).

- No claims can be enforced on them or by them.

- The "unbanked."

- Credit agents may enter into loan arrangements to smooth consumption subject to endogenous debt limits, as in Kehoe and Levine (1993). 


\section{NATURE OF THE ENVIRONMENT}

- Cash agents are anonymous households who may only use currency to smooth income fluctuations, as in Bewley (1980).

- No claims can be enforced on them or by them.

- The "unbanked."

- Credit agents may enter into loan arrangements to smooth consumption subject to endogenous debt limits, as in Kehoe and Levine (1993).

- Credit agents who default are forever excluded from the loan market and must instead use currency. 


\section{NATURE OF THE ENVIRONMENT}

- Cash agents are anonymous households who may only use currency to smooth income fluctuations, as in Bewley (1980).

- No claims can be enforced on them or by them.

- The "unbanked."

- Credit agents may enter into loan arrangements to smooth consumption subject to endogenous debt limits, as in Kehoe and Levine (1993).

- Credit agents who default are forever excluded from the loan market and must instead use currency.

- Future inflation rates will impact the payoff to default. 


\section{THE MONETARY AUTHORITY, BRIEF VERSION}

- Benevolent social planner chooses a constant inflation rate at which cash agents can trade ... 


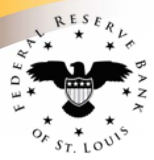

\section{THE MONETARY AUTHORITY, BRIEF VERSION}

- Benevolent social planner chooses a constant inflation rate at which cash agents can trade ...

- ... and directly selects consumption vectors for credit agents who may either accept their allocations or behave like cash agents in perpetuity. 


\section{THE MONETARY AUTHORITY, BRIEF VERSION}

- Benevolent social planner chooses a constant inflation rate at which cash agents can trade ...

- ... and directly selects consumption vectors for credit agents who may either accept their allocations or behave like cash agents in perpetuity.

- The inflation target in this economy is similar to an optimal tax subject to an incentive constraint as understood by Mirrlees (1971). 


\section{COSTS AND BENEFITS OF POSITIVE INFLATION}

- Positive rates of inflation impose a tax on cash agents ... 


\section{COSTS AND BENEFITS OF POSITIVE INFLATION}

- Positive rates of inflation impose a tax on cash agents ...

- ... and confer two benefits on credit agents: 


\section{COSTS AND BENEFITS OF POSITIVE INFLATION}

- Positive rates of inflation impose a tax on cash agents ...

- ... and confer two benefits on credit agents:

- a transfer of resources from the cash sector, and 


\section{COSTS AND BENEFITS OF POSITIVE INFLATION}

- Positive rates of inflation impose a tax on cash agents ...

- ... and confer two benefits on credit agents:

- a transfer of resources from the cash sector, and

- a reduction in the default payoff which brings about higher debt limits. 
- Pure equal-treatment planning problem would choose a periodic consumption sequence for each agent. 


\section{INFLATION TARGETING AS A PLANNING PROBLEM}

- Pure equal-treatment planning problem would choose a periodic consumption sequence for each agent.

- It would assign $\left(c_{H}, c_{L}\right)$ to high income and low income credit agents, and consumption $\left(x_{H}, x_{L}\right)$ to the corresponding cash agents. 
- Pure equal-treatment planning problem would choose a periodic consumption sequence for each agent.

- It would assign $\left(c_{H}, c_{L}\right)$ to high income and low income credit agents, and consumption $\left(x_{H}, x_{L}\right)$ to the corresponding cash agents.

- Equivalent to lump-sum taxes on some agents and lump-sum subsidies to others. 


\section{INFLATION TARGETING AS A PLANNING PROBLEM}

- Pure equal-treatment planning problem would choose a periodic consumption sequence for each agent.

- It would assign $\left(c_{H}, c_{L}\right)$ to high income and low income credit agents, and consumption $\left(x_{H}, x_{L}\right)$ to the corresponding cash agents.

- Equivalent to lump-sum taxes on some agents and lump-sum subsidies to others.

- Because inflation is a distortionary tax, we define a modified planning problem. 


\section{MODIFIED PLANNING PROBLEM}

- First, the monetary authority sets a constant inflation factor $\pi$. 


\section{MODIFIED PLANNING PROBLEM}

- First, the monetary authority sets a constant inflation factor $\pi$.

- Next, given $\pi$, high income cash agents choose a periodic consumption vector $\left(x_{H}, x_{L}\right) \geq 0$ to maximize stationary discounted utility

$$
\frac{1}{1-\beta^{2}}\left[u\left(x_{H}\right)+\beta u\left(x_{L}\right)\right]
$$

subject to

$$
\begin{gathered}
x_{H} \leq 1+\alpha, \\
x_{H}+\pi x_{L}=1+\alpha+\pi(1-\alpha), \\
u\left(x_{H}\right)+\beta u\left(x_{L}\right) \geq u(1+\alpha)+\beta u(1-\alpha)
\end{gathered}
$$


- First, the monetary authority sets a constant inflation factor $\pi$.

- Next, given $\pi$, high income cash agents choose a periodic consumption vector $\left(x_{H}, x_{L}\right) \geq 0$ to maximize stationary discounted utility

$$
\frac{1}{1-\beta^{2}}\left[u\left(x_{H}\right)+\beta u\left(x_{L}\right)\right]
$$

subject to

$$
\begin{gathered}
x_{H} \leq 1+\alpha, \\
x_{H}+\pi x_{L}=1+\alpha+\pi(1-\alpha), \\
u\left(x_{H}\right)+\beta u\left(x_{L}\right) \geq u(1+\alpha)+\beta u(1-\alpha)
\end{gathered}
$$

- (1) nonnegative currency; (2) money balances are used up to smooth consumption in low income dates; (3) agents can renounce money and consume endowments. 


\section{MORE ON THE MODIFIED PLANNING PROBLEM}

- Let $x_{H}(\pi)$ and $x_{L}(\pi)$ solve the previous problem. Given $\pi$, the planner now chooses consumption values $\left(c_{H}, c_{L}\right) \geq 0$ for credit households to maximize the equal-treatment welfare function

$$
\frac{1}{1-\beta^{2}}\left[u\left(c_{H}\right)+u\left(c_{L}\right)\right]
$$

subject to the resource constraint

$$
\lambda\left(c_{H}+c_{L}\right)+(1-\lambda)\left[x_{H}(\pi)+x_{L}(\pi)\right]=2,
$$

and the participation constraint

$$
u\left(c_{H}\right)+\beta u\left(c_{L}\right) \geq u\left[x_{H}(\pi)\right]+\beta u\left[x_{L}(\pi)\right] .
$$




\section{MORE ON THE MODIFIED PLANNING PROBLEM}

- Let $x_{H}(\pi)$ and $x_{L}(\pi)$ solve the previous problem. Given $\pi$, the planner now chooses consumption values $\left(c_{H}, c_{L}\right) \geq 0$ for credit households to maximize the equal-treatment welfare function

$$
\frac{1}{1-\beta^{2}}\left[u\left(c_{H}\right)+u\left(c_{L}\right)\right]
$$

subject to the resource constraint

$$
\lambda\left(c_{H}+c_{L}\right)+(1-\lambda)\left[x_{H}(\pi)+x_{L}(\pi)\right]=2,
$$

and the participation constraint

$$
u\left(c_{H}\right)+\beta u\left(c_{L}\right) \geq u\left[x_{H}(\pi)\right]+\beta u\left[x_{L}(\pi)\right] .
$$

- Equal treatment of high income and low income households means that the discounted utilities are weighted equally. This gives the welfare function above. 


\section{MORE ON THE MODIFIED PLANNING PROBLEM}

- If $c_{H}(\pi)$ and $c_{L}(\pi)$ solve the previous problem for a given $\pi>0$, the planner selects the stationary inflation factor $\pi$ to maximize the social welfare function

$$
\begin{aligned}
\mathcal{W}(\pi, \delta)=\delta\left\{u\left[c_{H}(\pi)\right]\right. & \left.+u\left[c_{L}(\pi)\right]\right\} \\
+ & (1-\delta)\left\{u\left[x_{H}(\pi)\right]+u\left[x_{L}(\pi)\right]\right\}
\end{aligned}
$$




\section{MORE ON THE MODIFIED PLANNING PROBLEM}

- If $c_{H}(\pi)$ and $c_{L}(\pi)$ solve the previous problem for a given $\pi>0$, the planner selects the stationary inflation factor $\pi$ to maximize the social welfare function

$$
\begin{aligned}
\mathcal{W}(\pi, \delta)=\delta\left\{u\left[c_{H}(\pi)\right]\right. & \left.+u\left[c_{L}(\pi)\right]\right\} \\
+ & (1-\delta)\left\{u\left[x_{H}(\pi)\right]+u\left[x_{L}(\pi)\right]\right\} .
\end{aligned}
$$

- This SWF assigns equal weights to members of the same group but potentially different weights to different groups. 


\section{MORE ON THE MODIFIED PLANNING PROBLEM}

- If $c_{H}(\pi)$ and $c_{L}(\pi)$ solve the previous problem for a given $\pi>0$, the planner selects the stationary inflation factor $\pi$ to maximize the social welfare function

$$
\begin{aligned}
\mathcal{W}(\pi, \delta)=\delta\left\{u\left[c_{H}(\pi)\right]\right. & \left.+u\left[c_{L}(\pi)\right]\right\} \\
& +(1-\delta)\left\{u\left[x_{H}(\pi)\right]+u\left[x_{L}(\pi)\right]\right\} .
\end{aligned}
$$

- This SWF assigns equal weights to members of the same group but potentially different weights to different groups.

- A strictly utilitarian SWF would have equal weights for all, that is, $\delta=\lambda$. 


\section{OPTIMUM INFLATION WITHOUT INCENTIVE CONSTRAINTS}

- To build up intuition, we first solve the planner's problem ignoring for the moment the incentive constraints. 


\section{OPTIMUM INFLATION WITHOUT INCENTIVE CONSTRAINTS}

- To build up intuition, we first solve the planner's problem ignoring for the moment the incentive constraints.

- We allow lump-sum income transfers. 


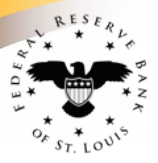

\section{OPTIMUM INFLATION WITHOUT INCENTIVE CONSTRAINTS}

- To build up intuition, we first solve the planner's problem ignoring for the moment the incentive constraints.

- We allow lump-sum income transfers.

- The planner then maximizes the SWF subject to the economy's resource constraint. 

CONSTRAINTS

- To build up intuition, we first solve the planner's problem ignoring for the moment the incentive constraints.

- We allow lump-sum income transfers.

- The planner then maximizes the SWF subject to the economy's resource constraint.

- This gives a first best solution with $\pi=\beta, R^{N}=1$, and smooth consumption for both groups of agents. 


\section{SECOND BEST}

- Suppose that the planner cannot impose a lump-sum tax on any agent but must instead use inflation or deflation and redistribute the resulting seignorage from one group to another. 


\section{SECOND BEST}

- Suppose that the planner cannot impose a lump-sum tax on any agent but must instead use inflation or deflation and redistribute the resulting seignorage from one group to another.

- The planner must now choose $\left(\pi, c_{H}, c_{L}\right)$ to solve the modified planning problem, but still ignoring the incentive constraints. 


\section{SECOND BEST}

- Suppose that the planner cannot impose a lump-sum tax on any agent but must instead use inflation or deflation and redistribute the resulting seignorage from one group to another.

- The planner must now choose $\left(\pi, c_{H}, c_{L}\right)$ to solve the modified planning problem, but still ignoring the incentive constraints.

- Suppose $\delta=1$, no welfare weight on the cash community. Then the planner chooses maximal seigniorage $\tilde{\pi}$ and smooths the consumption of the credit community completely. 


\section{SECOND BEST}

- Suppose that the planner cannot impose a lump-sum tax on any agent but must instead use inflation or deflation and redistribute the resulting seignorage from one group to another.

- The planner must now choose $\left(\pi, c_{H}, c_{L}\right)$ to solve the modified planning problem, but still ignoring the incentive constraints.

- Suppose $\delta=1$, no welfare weight on the cash community. Then the planner chooses maximal seigniorage $\tilde{\pi}$ and smooths the consumption of the credit community completely.

- Suppose $\delta=0$, no welfare weight on the credit community. Then the planner will push the inflation factor as close to zero as possible. 


\section{MORE ON SECOND BEST}

- The second best trades off these two extreme cases.

\section{THEOREM}

The second best optimum allocation under a utilitarian social welfare function satisfies $\left(c_{H}, c_{L}, x_{H}, x_{L}\right)=\left(c^{* *}, c^{* *}, x_{H}\left(\pi^{* *}\right), x_{L}\left(\pi^{* *}\right)\right)$. It is supported by a "modified Friedman rule" for some inflation factor $\pi^{* *} \in(\beta, 1)$, and a nominal yield such that $R^{N}=\pi^{* *} / \beta>1$.

PROOF.

See the appendix. 


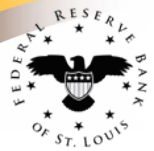

\section{KEY ASSUMPTIONS}

- A1. Income shares cannot be "too variable." 

KEY ASSUMPTIONS

- A1. Income shares cannot be "too variable."

- A2. Income shares cannot be "too smooth." 


\section{KEY ASSUMPTIONS}

- A1. Income shares cannot be "too variable."

- A2. Income shares cannot be "too smooth."

- A3. It is within the power of the central planner to lower the rate of return facing users of cash to the point where the incentive constraint on credit users becomes slack. 


\section{KEY ASSUMPTIONS}

- A1. Income shares cannot be "too variable."

- A2. Income shares cannot be "too smooth."

- A3. It is within the power of the central planner to lower the rate of return facing users of cash to the point where the incentive constraint on credit users becomes slack.

- Call the associated inflation factor $\bar{\pi}$. 


\section{KEY ASSUMPTIONS}

- A1. Income shares cannot be "too variable."

- A2. Income shares cannot be "too smooth."

- A3. It is within the power of the central planner to lower the rate of return facing users of cash to the point where the incentive constraint on credit users becomes slack.

- Call the associated inflation factor $\bar{\pi}$.

- Perhaps more controversial? 


\section{KEY ASSUMPTIONS}

- A1. Income shares cannot be "too variable."

- A2. Income shares cannot be "too smooth."

- A3. It is within the power of the central planner to lower the rate of return facing users of cash to the point where the incentive constraint on credit users becomes slack.

- Call the associated inflation factor $\bar{\pi}$.

- Perhaps more controversial?

- "The market for unsecured credit can be made to work perfectly." 


\section{LEMMA 2}

LEMMA

Define $\mathcal{W}_{\pi}(\pi, \delta)=\partial \mathcal{W} / \partial \pi$. Then $(a) \mathcal{W}_{\pi}(\pi, \delta)<0$

$\forall(\pi, \delta) \in[\bar{\pi}, \tilde{\pi}] \times[0, \lambda]$, and (b) $\lim _{\pi \rightarrow 1} \mathcal{W}_{\pi}(\pi, \delta)=+\infty$ when $\pi$ converges from above.

- Part (a) intuition. To raise $\pi$ above $\bar{\pi}$ does not improve the ability of the planner to smooth the consumption of the credit community any further. Doing so merely transfers income from the cash community. This transfer will reduce social welfare except when $\delta>\lambda$. 


\section{LEMMA 2}

LEMMA

Define $\mathcal{W}_{\pi}(\pi, \delta)=\partial \mathcal{W} / \partial \pi$. Then $(a) \mathcal{W}_{\pi}(\pi, \delta)<0$

$\forall(\pi, \delta) \in[\bar{\pi}, \tilde{\pi}] \times[0, \lambda]$, and (b) $\lim _{\pi \rightarrow 1} \mathcal{W}_{\pi}(\pi, \delta)=+\infty$ when $\pi$ converges from above.

- Part (a) intuition. To raise $\pi$ above $\bar{\pi}$ does not improve the ability of the planner to smooth the consumption of the credit community any further. Doing so merely transfers income from the cash community. This transfer will reduce social welfare except when $\delta>\lambda$.

- Part (b) intuition. A small increase in the inflation tax creates a credit market where one would otherwise not exist. 


\section{LEMMA 3}

LEMMA

$\mathcal{W}(\pi, \delta)$ is not defined for $\pi<1$. It is decreasing in $\pi$ for $\pi \in(\tilde{\pi}, 1 / \bar{R})$ and constant for $\pi \geq 1 / \bar{R}$.

- Deflation violates the participation constraint for high income credit households. 
LEMMA

$\mathcal{W}(\pi, \delta)$ is not defined for $\pi<1$. It is decreasing in $\pi$ for $\pi \in(\tilde{\pi}, 1 / \bar{R})$ and constant for $\pi \geq 1 / \bar{R}$.

- Deflation violates the participation constraint for high income credit households.

- The outcome of any deflation is that money has a higher payoff than credit. 


\section{THEOREM 4}

\section{THEOREM}

Suppose assumptions $\mathbf{A 1}, \mathbf{A} 2$, and $\mathbf{A} 3$ hold, and $0<\delta \leq \lambda$. Then the optimum inflation factor is $\pi^{\star}(\delta)>1$ and the associated nominal interest yield, $R^{N} \in\left(\pi^{\star}(\delta), \pi^{\star}(\delta) / \beta\right)$, is even higher. 


\section{CONCLUSIONS AND EXTENSIONS}

- In this paper, the optimal inflation target should strike a balance between the deadweight loss from inflation and the potential improvement in credit market conditions. 


\section{CONCLUSIONS AND EXTENSIONS}

- In this paper, the optimal inflation target should strike a balance between the deadweight loss from inflation and the potential improvement in credit market conditions.

- Main conclusion: independent central banks will set low positive inflation targets in economies that possess highly developed financial markets. 


\section{CONCLUSIONS AND EXTENSIONS}

- In this paper, the optimal inflation target should strike a balance between the deadweight loss from inflation and the potential improvement in credit market conditions.

- Main conclusion: independent central banks will set low positive inflation targets in economies that possess highly developed financial markets.

- U.S.A.: One to two percent. 


\section{CONCLUSIONS AND EXTENSIONS}

- In this paper, the optimal inflation target should strike a balance between the deadweight loss from inflation and the potential improvement in credit market conditions.

- Main conclusion: independent central banks will set low positive inflation targets in economies that possess highly developed financial markets.

- U.S.A.: One to two percent.

- Republic of South Africa: Three to six percent. 


\section{CONCLUSIONS AND EXTENSIONS}

- In this paper, the optimal inflation target should strike a balance between the deadweight loss from inflation and the potential improvement in credit market conditions.

- Main conclusion: independent central banks will set low positive inflation targets in economies that possess highly developed financial markets.

- U.S.A.: One to two percent.

- Republic of South Africa: Three to six percent.

- Sounds like "comfort zones" articulated by central bankers. 